REVISTA ECONOMÍA

Vol. 69, N. ${ }^{\circ}$ Io9 (mayo), 6I-78

\title{
CAPITALISMO, SOCIEDAD DE MERCADO Y SOLIDARIDAD. UNA MIRADA CRÍTICA A LOS POSTULADOS DE LA ECONOMÍA SOCIAL Y SOLIDARIA
}

\author{
DIEGO BENÍTEZ
}

Flacso, Ecuador

Recepción manuscrito: 6 de enero de 2017

Aceptación versión final: 15 de abril de 2017

\begin{abstract}
RESUMEN Que el capitalismo, caracterizado por la economía de mercado, es un sistema que menoscaba los valores morales y la solidaridad, es una idea tomada como axioma por un grupo destacado de intelectuales identificados con la Economía Social y Solidaria. Este sería el punto de partida para proponer sistemas alternativos en los que la solidaridad vuelva a ser el centro de la actividad económica. Sin embargo, esta afirmación parece infundada. El presente documento aborda este debate desde una perspectiva crítica. Se propone que la Economía Social y Solidaria adopte la posibilidad de que en el capitalismo sí existe la solidaridad, exponiendo para ello argumentos tomados tanto de la sociología como de la economía.
\end{abstract}

PALABRAS CLAVE Capitalismo, sociedad de mercado, solidaridad, cooperación, acción colectiva.

ABSTRACT The idea that capitalism, characterized by the market economy, is a system that undermine moral values and solidarity is taken as axiomatic by a notable group of intellectuals identified with the Social and Solidarity Economy. This is a starting point for proposing alternative systems in which solidarity becomes again the center of the economic activity. However, this statement looks ungrounded. This article addresses this debate from a critical perspective. In this paper, I argue that Social and Solidarity Economy should accept the possibility that under capitalism solidarity does exist. I expose arguments both from sociology and economics.

KEYWORDS Capitalism, market society, solidarity, cooperation, collective action.

JEL CODES B1, B2, B3, B4, B5.

\section{INTRODUCCIÓN}

¿Es la solidaridad un valor contrario a la economía de mercado y al capitalismo? Algunos autores opinan que sí. De manera contemporánea, los autores identificados con la otra economía - la economía social, la economía solidaria, la economía popular y otros términos parecidossostienen que los términos «solidaridad» y «economía» han estado tradicionalmente disociados. «Las palabras economía y solidaridad, siendo habituales tanto en el lenguaje común como en el pensamiento culto, formaban parte de discursos separados» (Razeto, 1997, p. 3). Una de las razones que originaría esta separación sería la pretensión de posicionar a la Economía como 
una «ciencia» que se ocupa de los hechos y no en valoraciones «morales o éticas» donde radicaría la solidaridad. De forma general, los autores que suscriben estas ideas (Laville, 2009) (Acosta, Martínez y Coraggio, 2011) (Voutto, 2003) han mantenido una especie de lucha de resistencia - en el campo de las ideas - ante el capitalismo, generador — según sus convicciones- de la pobreza, la desigualdad, las injusticias, la exclusión y otros males sociales que afectan dramáticamente a las poblaciones, principalmente, de los países no desarrollados.

No obstante, durante la lucha, ha sido evidente - más para algunos que para otros- que el asistencialismo del Estado no es la solución, lo que conlleva a la necesidad de "volver a encastrar la solidaridad en la sociedad» (Laville, 2009, p. 11). Detrás de esta afirmación, está la idea de que en la economía tradicional «la solidaridad era una forma de intercambio económico» (Laville, 2009, p. 11), y que el desarrollo del capitalismo, expresado tanto en el mercado como en el Estado, ha ido dejando a la solidaridad como una expresión marginal, de poco interés en las economías modernas. La solidaridad prevalecería no solo en la economía tradicional, sino también en la que se realiza entre pobres. Argumentos como el siguiente son comunes entre los autores de la otra economía:

La economía popular en sus varias manifestaciones y formas contiene importantes elementos
de solidaridad que es importante reconocer y destacar. Hay solidaridad en ella, en primer lugar,
porque la cultura de los grupos sociales más pobres es naturalmente más solidaria que la de los
grupos sociales de mayores ingresos. La experiencia de la pobreza, de la necesidad experimen-
tada como urgencia cotidiana de asegurar la subsistencia, lleva a muchos a vivenciar la impor-
tancia de compartir lo poco que se tiene, de formar comunidades y grupos de ayuda mutua y
de recíproca protección. El mundo popular, puesto a hacer economía, la hace «a su modo», con
sus valores, con sus modos de pensar, de sentir, de relacionarse y de actuar. (Razeto, 1997, p. 16)

Sin embargo, la afirmación de que en la economía tradicional —o generalizando la expresión a economías no capitalistas o no mercantiles, incluyendo la economía de la pobreza- la solidaridad es un valor que sobresale de alguna manera diferente que en las economías capitalistas o de mercado, parece infundada. El presente artículo tiene por finalidad argumentar a favor de que en el capitalismo y en la economía de mercado sí puede surgir la solidaridad. Se propone que la Economía Social y Solidaria (Ess) adopte la posibilidad de que en el capitalismo sí existe la solidaridad, exponiendo para ello, argumentos tomados tanto de la sociología como de la economía.

Para lograr este propósito, antes es necesario hacer dos aclaraciones. Primero, definir el objeto de esta crítica, es decir, la Ess. Segundo, definir a qué refiere en este artículo con capitalismo, economía de mercado y solidaridad. Una vez aclarados estos puntos se procede a hacer una breve revisión histórica de los argumentos a favor y en contra de que el capitalismo y la economía de mercado promueven el egoísmo o deterioran valores morales superiores y la solidaridad. Luego, se exponen argumentos contemporáneos, tomados tanto de la economía como de la sociología, a favor de que en el capitalismo y la economía de mercado sí puede surgir la solidaridad y que parece infundada la idea de que en las sociedades tradicionales, no mercantiles o no capitalistas, la solidaridad es un valor que sobresale de forma diferente que en las economías capitalistas modernas caracterizadas por una gran penetración del mercado. Finalmente se ofrece una conclusión. 


\section{ACLARACIONES PRELIMINARES}

Para este ensayo, se define como Ess al conjunto de ideas que buscan convencer sobre la necesidad de cambiar la forma de hacer economía, aglutinadas en diferentes denominaciones como economía solidaria, economía popular, economía social, economía de la solidaridad, otra economía, entre otras. Autores como Guerra (2014) le otorgan la categoría de escuela de pensamiento latinoamericana, en virtud de que un número importante de universidades del continente han instaurado cátedras alrededor de la Ess, y de que se han creado redes académicas, como Unitrabalho en Brasil -integrada por más de ochenta universidades-. En el campo de las acciones, muchas organizaciones sociales, sindicatos y cooperativas han adherido a los postulados de la Ess; los cuales incluso han sido integrados en las constituciones políticas de países como Venezuela, Bolivia y Ecuador. A estas ideas se les atribuye antecedentes doctrinales y teóricos europeos, principalmente agrupados en el socialismo utópico, el movimiento cooperativo, el movimiento del solidarismo, el personalismo comunitario, la economía humana de Lebret, entre otras doctrinas (Guerra, 2014). Aunque las ideas alrededor de la Ess son muy variadas, y provienen de diferentes escuelas de pensamiento, pueden identificarse una serie de autores emblemáticos entre los que destacan Luis Razeto (1984), José Luis Coraggio (2008), Paul Singer (2012) y Luis Inácio Gaiger (2007), todos estos latinoamericanos, aunque sus ideas también están asociadas a autores europeos como Jean-Louis Laville (2009).

Reduciendo al mínimo a la Ess, aun corriendo el riesgo de simplificarla en extremo, puede expresarse que sus ideas coinciden en el estudio y la búsqueda de un modo de producción alternativo a los modos capitalista y estatista predominantes en la sociedad de mercado, lo cual abarcaría el plano de la producción (Singer, 2007), de la distribución —-mediante relaciones económicas que permitirían una mayor integración social como las donaciones, reciprocidad, «comensalidad» y cooperación-, y del consumo - consumo comunitario, autoconsumo, simplicidad y austeridad, que llevaría incluso a una valoración mucho mayor de los problemas ecológicos- (Guerra, 2014).

De acuerdo a Singer (2007), el modo de producción «solidario» sería una especie de híbrido entre el capitalismo y la pequeña producción de mercancías. Con el primero, compartiría la característica de que la utilización y alcance de los medios de producción rebasan el ámbito de quienes los poseen — principio de socialización de los medios de producción-, mientras que con el segundo compartiría el principio de la unidad entre posesión y utilización de los medios de producción y distribución (Singer, 2007, p. 61). ${ }^{1}$ Esto sugiere una forma alternativa de organizar la producción - y la distribución, e incluso el consumo, según autores como Guerra-, alrededor de unidades que ya no serían las empresas, sino las cooperativas - y también otras formas de asociación como las redes de comercio justo, mutualistas, y otras-, que tendrían ciertas características fundamentales que las diferenciarían de las unidades de producción capitalista. ${ }^{2}$

Hacer una tipología de las unidades productivas de la Ess requeriría de un trabajo muy minucioso y, por ende, extenso, que escapa al alcance de este trabajo. Esto en virtud de que las fronteras, en el ámbito de las prácticas, entre las «unidades solidarias» y las empresas capitalistas convencionales pueden ser muy tenues en varios aspectos. Para ilustrar este punto, basta con constatar, a manera de ejemplo, tres tipos de hechos - aunque si se quisiera agotar 
el tema, podrían enumerarse algunos más-: i) a menudo - casi siempre- las cooperativas también contratan mano de obra asalariada, con lo cual los cooperados entran a operar como capitalistas, tendiendo que enfrentar el mismo tipo de conflictos que ocurren entre empresas y trabajadores; ii) algunas cooperativas de ahorro, cuando crecen, tienen estructuras organizativas muy similares a las de los bancos pequeños; y iii) algunos autores de la Ess, como Singer, consideran que es posible que empresas capitalistas convencionales sean consideradas sociales: «Yo creo que cualquier empresa democrática, igualitaria y autogestionaria - cooperativa o no- ya es socialista. Es una experiencia socialista, aunque sea puntual [...]» (Singer, 2000).

Evitando entrar en los detalles acerca de las unidades de producción solidarias, es preciso destacar que se les atribuye ciertas bondades que las diferenciarían de forma radical de las unidades de producción capitalista. Guerra (2014), destaca de Razeto algunas de ellas: i) la posibilidad de cooperar en el trabajo, lo cual acrecienta la eficiencia de la fuerza laboral, ii) el uso compartido de conocimientos e informaciones que da lugar a un importante elemento de creatividad social, iii) la adopción colectiva de decisiones, iv) una mejor integración de los distintos componentes funcionales de la empresa - que reducen los conflictos y los costos derivados-, v) la satisfacción de necesidades de convivencia y participación — beneficios no monetarios-, y vi) desarrollo personal de los sujetos involucrados, entre otros.

La forma en que las unidades solidarias lograrían tan buenos resultados, en comparación con sus contrapartes capitalistas, sería que las primeras rescatarían ciertos valores de solidaridad y de colectivismo que las segundas habrían olvidado por su inmersión en la lógica individualista que le impone la sociedad de mercado y el capitalismo. Precisamente, éste es el objeto de la crítica del presente artículo, pues el supuesto tomado como axioma de que la economía de mercado y el capitalismo corroen la solidaridad y los valores morales, no parece tener sustento; así como tampoco la afirmación de que, en las sociedades tradicionales, precapitalistas o populares, la solidaridad sea un valor que sobresale de manera especial respecto a las sociedades modernas de mercado o capitalistas.

Esto da pie a la segunda aclaración necesaria respecto a qué se entiende, en el marco de este artículo, por capitalismo y sociedad de mercado, y por qué se lo usa aquí como términos sinónimos o intercambiables. Algunos autores de la Ess coinciden en señalar que el capitalismo es un modo de producción en el cual «los medios de producción y de distribución, así como el trabajo, se vuelven mercancías apropiadas de forma privada» (Singer, 2007, p. 60). Está caracterizado por una alta concentración de los medios de producción en pocas manos, mientras que la «mayoría se limita a la posesión de su capacidad individual de trabajo». Otros autores - por fuera de la Ess-, como Martínez González-Tablas (2000), proveen definiciones bastante más complejas, caracterizándolo «como un entramado de procesos y relaciones que, a partir de unos componentes característicos y una lógica específica, desembocan, periodo tras periodo, en un determinado producto social» (Martínez González-Tablas, 200o, p. 68).

No se pretende profundizar en la explicación que hace Martínez González-Tablas acerca del sistema económico capitalista (SEC), pero sí destacar su posición expresa de que no debe confundírselo con la «pura y aséptica economía de mercado».3 La razón es que, desde su análisis, la economía de mercado es solo una parte del SEC, que también está conformado por lógicas de funcionamiento, cambiantes en la historia, que le permiten su supervivencia. Esto 
porque este autor procura explicar el proceso de globalización de manera integral desde la mirada de la Economía Política.

Para el presente trabajo, es indistinto el uso de uno y otro término porque los autores de la ESS, cuando consideran que el capitalismo menoscaba la solidaridad, no hacen diferencia alguna con la sociedad de mercado, destacando solo la destrucción de lo colectivo, en beneficio del individualismo. Si señalaran alguna diferencia, en el sentido argumentado por Martínez González-Tablas, tampoco habría alguna repercusión en el análisis aquí planteado porque la sociedad de mercado sería una parte integral del SEC, con lo cual, le aportaría sus deficiencias y vicios. Es oportuno rescatar que la conceptualización que realiza Polanyi (1992) acerca de la sociedad de mercado es muy cercana a la utilizada por los autores de la Ess para definir el capitalismo, precisando que la economía de mercado, como subsistema del sistema social, solo puede existir bajo la presencia de un patrón institucional específico que permite la existencia de las llamadas «mercancías ficticias», para referirse a la mano de obra, la tierra y el dinero. Ésta es otra razón para considerar, en el marco de este artículo, como intercambiables estos dos términos.

Finalmente, es importante precisar que, para efectos de este artículo, la solidaridad tiene una acepción moral - es un valor moral o una norma de comportamiento ético- que induce a las personas a actuar en favor de los otros o de la colectividad - se puede generalizar a actuar gentilmente para los demás-, y se la define en contraposición al egoísmo, que motivaría a las personas a buscar su interés individual. Se considera que esta definición es abarcativa de las distintas interpretaciones y conceptualizaciones que pueden hacerse del término. De esta forma, cuando en lo posterior se habla de egoísmo o individualismo, se refiere del inverso de la solidaridad y viceversa.

En conclusión se está consciente de que el capitalismo es un modo de producción cuya definición puede dar espacio a mucho debate y análisis, pero este artículo se vale del hecho de que la caracterización de sociedad de mercado expuesta por Polanyi es muy similar a la de capitalismo usada por algunos de los autores de la ess. Aún si no se acepta lo equiparable de los términos, el individualismo - o egoísmo, como definición inversa de la solidaridad- que caracterizaría a la sociedad de mercado, también afectaría a la sociedad capitalista.

\section{BREVE HISTORIA DEL DEBATE}

En los orígenes del capitalismo, la idea del comercio - o del mercado- como corruptor de los valores morales era el argumento de los sectores conservadores, quizás porque defendían sus privilegios. Éstos veían con desconfianza a los comerciantes y a la incipiente burguesía. Los mercaderes y los primeros industriales eran vistos como una amenaza a la hegemonía de las clases feudales, aristocráticas y religiosas. Las influencias externas ponían en peligro el sistema de creencias y símbolos que gobernaban a la sociedad. Posteriormente, Marx y Engels (2006) usarían argumentos similares para referirse a algunos efectos ocasionados por el desarrollo del capitalismo: «Dondequiera que ha conquistado el poder, la burguesía ha destruido las relaciones feudales, patriarcales idílicas. Las abigarradas ligaduras feudales que ataban al hombre a sus 'superiores naturales', las ha desgarrado sin piedad, para no dejar subsistir otro vínculo entre los hombres que el del frío interés, el cruel 'pago al contado' [...]» (Marx y Engels, 2006, p. 34). 
En el marxismo, este tipo de argumentos sería utilizado para describir la forma en que el capitalismo colonizaría todos los espacios de la sociedad. Posteriormente, al ser ciega la «fuerza del mercado», el capitalismo tendría el ímpetu necesario para destruir no solo los valores morales de las sociedades tradicionales, pero también aquellos esenciales para su propio éxito y supervivencia. En parte, este es el origen de la metáfora que indica que el capitalismo lleva la «semilla de su propia destrucción». ${ }^{4}$ De esta forma, las ideas que sostienen que el capitalismo corroe valores morales como la solidaridad podrían tener su origen en el marxismo, aunque el tipo de argumentos utilizados sean similares a los que apelaban los conservadores en el siglo XVI en contra de los mercaderes y la incipiente burguesía para defender sus privilegios.

Ya en el siglo xx, desde la Escuela de Fráncfort, autores como Max Horkheimer retoman el pesimismo acerca de los efectos que el desarrollo del sistema económico tiene sobre la moral. En su libro Crítica de la razón instrumental (Horkheimer, 2002), publicado por primera vez en 1948, el autor realiza una crítica radical y universal, es decir, total, a la Ilustración, a la Modernidad y a la civilización occidental. El autor ve en el desarrollo de la civilización tanto del capitalismo como del comunismo de la época- una paradoja en la que, por un lado, existe un gran desarrollo tecnológico que le permite a la sociedad tener mejores medios para lograr sus fines y, por el otro, que esos fines sean contradictorios a la razón. ${ }^{5}$

Para los autores, en esta línea, la razón — razón objetiva, razón científica- representa la posibilidad de fijar objetivos superiores para la sociedad. Por su parte, el objeto de su crítica, la razón instrumental, que opera bajo la lógica del «dominio y la autoconservación», llevaría a las sociedades a situaciones «injustas» — como puede ser el caso de la pobreza o la desigualdad - o incluso catastróficas — como puede ser el caso de la guerra- ${ }^{6}$ Bajo el argumento de Horkheimer, el éxito del sistema económico garantiza esas injusticias y promueve las catástrofes.?

Mediante su identificación de conocimiento y ciencia el positivismo limita la inteligencia a funciones que resultan necesarias para la organización de un material ya tallado de acuerdo con el molde de la cultura comercial, esa cultura que la inteligencia debería precisamente criticar. Tal limitación, convierte la inteligencia en medio al servicio del aparato de producción y no, ciertamente, en instancia llamada a dominarlo, como desearían Hooks y sus amigos positivistas. (Horkheimer, 2002, p. 108)

De manera más contemporánea, Fred Hirsch (1976), en su influyente libro Límites sociales del crecimiento, desarrolla la noción del «agotamiento del legado moral» del capitalismo. Esta idea consiste en señalar que el mercado menoscaba los valores morales que son los fundamentos del sistema y que estaban presentes en los sistemas socioeconómicos precedentes, como es el caso del feudalismo. El autor lo expresa en los siguientes términos:

La moralidad social que ha servido como infraestructura del individualismo económico ha sido un legado del pasado precapitalista y preindustrial. Este legado ha disminuido con el tiempo y con el contacto corrosivo de los valores capitalistas activos, y de forma más general con el mayor anonimato y movilidad de la sociedad industrial. De esta forma, el sistema ha perdido el soporte externo que previamente le otorgaba el individuo. A medida que el comportamiento individual ha estado crecientemente dirigido a los intereses particulares, los hábitos e instintos 
basados en actitudes y objetivos comunales se han perdido. El debilitamiento de los valores sociales tradicionales ha hecho que las economías predominantemente capitalistas sean más difíciles de manejar. (Hirsch, 1976, pp. 117-118)

El argumento de Hirsch es que en los sistemas capitalistas se pone mucho - ¿demasiado? énfasis en los intereses particulares, lo que dificulta la provisión de bienes colectivos y la cooperación, necesarios para el funcionamiento del sistema en sus etapas posteriores.

Pese a la predominancia del tipo de ideas expuestas, hay que destacar que, a lo largo de la historia, también ha habido argumentos contrarios a los señalados hasta aquí. Partiendo desde el siglo XVIII, parece ser que filósofos como Montesquieu, William Robertson, Condorcet o Thomas Paine, coincidían en señalar que las prácticas comerciales iban acompañadas por conductas «gentiles», menos violentas, más civilizadas. En su obra Del espíritu de las leyes, publicada originalmente en 1747, Montesquieu (1987) hace alusión a las bondades de las prácticas comerciales, en comparación con las prácticas de los reyes, la aristocracia o los déspotas. En diferentes partes de su libro pueden encontrarse expresiones relacionadas a la práctica del comercio como la que se cita a continuación:

Verdad es que cuando la democracia está fundada en el comercio, puede ocurrir que algunos particulares posean grandes riquezas sin que se corrompan las costumbres, porque el espíritu de comercio lleva consigo el de frugalidad, economía, moderación, trabajo, prudencia, tranquilidad, orden y regla. (Montesquieu, 1987, p. 37).

De forma similar, Thomas Paine (1951) en su obra Los derechos del hombre, publicada originalmente en 1792, afirma que el comercio «es un sistema pacífico que opera para hacer más cordial a la humanidad [...] volviendo útiles unos a otros, tanto a las Naciones como a los Individuos [...] La invención del comercio es el mayor aporte que se haya hecho a la civilización universal, no seguida ni de cerca por los principios morales» (Paine, 1951, p. 81).

No está claro cuáles habrían sido los mecanismos por los que el comercio habría tenido tan virtuosos efectos sobre la moral. La literatura del siglo XviII no hace énfasis en esto, quizás porque a los ojos de los contemporáneos era obvio. Sin embargo, existe un manual del comerciante, Traité général du commerce de Samuel Ricard (1781), publicado primero en 1704, y reeditado posteriormente durante más de un siglo, que provee algunas pistas sobre dichos mecanismos. Aparentemente, los efectos virtuosos del comercio se darían por la necesidad que tendría el comerciante, si quiere ser exitoso, «de suprimir sus pasiones, físicas y morales, a favor del interés; cambiando el orgullo y la arrogancia por la flexibilidad y la vocación de servicio» (Ricard, 1781, p. 463).

Bastante tiempo después, bien avanzado el siglo xIx, Émile Durkheim abre la posibilidad de que en las sociedades capitalistas modernas surja un tipo de solidaridad distinta a la observada en las sociedades tradicionales. En su obra La división del trabajo social, el autor establece dos tipos de solidaridad; por un lado, está aquella basada en la semejanza y, por el otro, la basada en la complementariedad de virtudes diferentes (Durkheim, 1967).

Esta concepción, aparentemente contradictoria, habría tenido como antecedente algunos debates acerca de la amistad desde la época de los filósofos griegos. Aristóteles, por ejemplo, habría apuntado que «según unos, [la amistad] consiste en cierta semejanza y los que se 
parecen se quieren [...] Pero, según otros, por el contrario, todos los que se parecen son alfareros los unos para los otros [...] Así, Eurípides dice que la tierra reseca ama la lluvia, y que el cielo cargado de lluvia se precipita con amoroso furor sobre la tierra. Heráclito pretende que no se une más que lo que se opone, que la más hermosa armonía nace de las diferencias, que la discordia es la ley de todo devenir» (Durkheim, 1967, p. 54).

La solidaridad que surge de la igualdad, denominada por él como la solidaridad mecánica, habría prevalecido en las sociedades tradicionales. Por su parte, en las sociedades modernas, capitalistas, caracterizadas por una alta división del trabajo, predominaría el tipo de solidaridad que él denominó solidaridad orgánica, en alusión a los órganos de un organismo viviente. Entonces, según el argumento de Durkheim, no es que el capitalismo llegaría a destruir todo tipo de lazo social solidario, sino que — en cierto sentido - vendría a reemplazar un tipo de solidaridad por otro. Sin embargo, hay que señalar que para Durkheim la solidaridad orgánica no surge espontáneamente por la exposición de los individuos al capitalismo y al comercio. Para él, este tipo de solidaridad solo puede surgir en el seno de una sociedad preexistente, es decir, entre individuos donde previamente existen lazos morales. Incluso, advierte sobre las consecuencias contrarias en los casos en que esta condición no se cumple: «Si las relaciones que comienzan a establecerse en los periodos de tanteo no estuvieran sujetas a regla alguna, si ningún poder que moderara el conflicto de los intereses individuales, resultaría un caos de donde no podría salir ningún orden nuevo» (Durkheim, 1967, p. 235).

Además, para que surja la solidaridad orgánica, los sujetos deben tener un «contacto bastante íntimo para poder accionar y reaccionar unos sobre otros [...]» (Durkheim, 1967, p. 222). En conjunto, las condiciones planteadas por Durkheim para que surja la solidaridad orgánica hacen suponer que el resultado de la división del trabajo respecto a la moral de la sociedad no es obligatoriamente virtuoso. Esto queda claro cuando el autor desarrolla el concepto de «anomia» para referirse al estado de ciertas sociedades donde sus individuos, por falta de normas, no cuentan con las condiciones básicas para cumplir sus metas. Sin embargo, es preciso rescatar que, aunque no sea suficiente, la división del trabajo — rasgo característico del capitalismo- sí constituye para Durkheim una condición necesaria para lograr estados morales superiores. El siguiente fragmento, tomado de uno de los últimos párrafos de su libro, es muy elocuente en este sentido:

\footnotetext{
Ahora bien sabemos que no pueden formarse sociedades más vastas sin que se desarrolle la división del trabajo [...] Por lo tanto, podemos formular la siguiente proposición: el ideal de la fraternidad humana solo puede realizarse en la medida en que progresa la división del trabajo. (Durkheim, 1967, p. 422)
}

De esta manera, queda claro que, desde la visión de Durkheim, el capitalismo, caracterizado por la inusitadamente alta división del trabajo, es un sistema que puede conducir al ideal de la «fraternidad humana» o fraternidad entre todos los hombres. Por otro lado, es preciso destacar que, para el autor, la solidaridad adopta la forma de normas morales. En este sentido, la fraternidad entre todos los hombres podría interpretarse como un estado en el que las normas dominantes son aquellas que llaman a respetar las diferencias y que proveen valor a las personas en función de su individualidad. Si la sociedad avanza en este sentido, con valores 
como el respeto a la libertad de pensamiento o la igualdad de género, que hace unas pocas décadas hubieran sido inconcebibles, entonces ¿cómo suponer que en esta sociedad se esté degradando la solidaridad?

Otro tipo de argumentos a favor de que la economía de mercado podría generar lazos de solidaridad surgieron a finales del siglo xIx. Contemporáneo a Durkheim, Georg Simmel señala que la competencia, propia de las economías modernas, es una institución que fomenta la empatía y que construye fuertes lazos sociales. Simmel, conocido principalmente por su obra Filosofía del dinero (Simmel, 2013), hace énfasis en la integración de las funciones de los diversos conflictos en las sociedades modernas. En este contexto, señala a la competencia como una institución que fomenta la empatía y que construye fuertes lazos sociales, desde luego que no entre los competidores, pero entre ellos y una importante tercera parte, muchas veces no tomada en cuenta: el cliente. Según esta visión, la empatía y la solidaridad surgen porque cada una de las partes en competencia trata de permanecer tan cerca de sus clientes como les sea posible. En palabras de Simmel, «La competencia logra lo que normalmente solo el amor puede hacer: adivinar los deseos más íntimos del otro, incluso antes de que el propio beneficiario se perciba de ellos [...] En otras palabras, [la competencia] es una red tejida por lazos que son consecuencia de enfocarse en la voluntad, los sentimientos y los pensamientos de los semejantes» (Simmel, 1955, p. 61).

Con esta breve revisión histórica se pretende dejar establecido que ha habido distintos tipos de argumentos, a favor y en contra, del carácter destructor que tendría el capitalismo y la sociedad de mercado sobre la solidaridad. Pese a que los primeros han sobresalido en el ámbito de las ciencias sociales, y específicamente entre los autores de la Ess, los segundos no son menos importantes. Es probable que algunos de los argumentos contemporáneos que endilgan a la sociedad de mercado y al capitalismo valores egoístas e individualistas tengan su origen en algunas de las ideas aquí expuestas - aunque no se ha pretendido ser exhaustivos en la revisión-, pero una construcción teórico más rigurosa por parte de la Ess, requeriría tomar en cuenta también los argumentos que han sostenido lo contrario. A continuación se realiza una breve exposición de argumentos contemporáneos a favor de que en el capitalismo y la economía de mercado sí puede surgir la solidaridad.

\section{ARGUMENTOS CONTEMPORÁNEOS A FAVOR DE LA SOLIDARIDAD EN EL CAPITALISMO}

En principio, se esperaría que entre los economistas que defienden el sistema capitalista frente a las críticas de izquierda, existan numerosos exponentes que argumenten a favor de la idea de que los diferentes actos de compra-venta fraguan todo tipo de lazos sociales de confianza, amistad, sociabilidad, que ayuden a mantener unida a la sociedad. Sin embargo, esta temática ha estado tradicionalmente al margen de la discusión en la disciplina. Hirschman (1982) encuentra la explicación a este fenómeno en tres razones principales. Primero, en su pretensión de emular el rigor y la precisión cuantitativa de las ciencias naturales, los economistas considerarían poco útil las «necesariamente imprecisas especulaciones acerca de los efectos de las transacciones económicas en la cohesión social». Segundo, los economistas formados en la tradición clásica verían los efectos destructivos del capitalismo como un costo de corto plazo, 
necesario para obtener beneficios mayores en el largo plazo. Finalmente - la que el autor considera la más importante-, los economistas preferirían creer en el mercado ideal, con competencia perfecta, al que un gran número de compradores y vendedores, con información perfecta, y sin ningún contacto humano o social prolongado, acuden y en su interacción - sin regateos, negociaciones o acuerdos mutuos- logran la asignación más eficiente de recursos. ${ }^{8}$ Sin embargo, esta suerte de apatía por la temática estaría cambiando paulatinamente a juzgar por la evolución del debate en la disciplina en los últimos 20030 años.

Desde hace algunas décadas, un número creciente de economistas viene adoptando la preocupación acerca de qué factores hacen posible la cooperación en la especie humana, tal es el caso Elinor Ostrom (2011), con sus célebres estudios acerca del gobierno de los bienes comunes, que le hicieron acreedora del premio Nobel de Economía en 2009. En gran medida, su obra es una respuesta a la idea muy difundida entre los economistas - particularmente en las décadas de los sesenta y setenta- de que la cooperación humana era imposible y, como consecuencia, los recursos comunes estaban destinados a desaparecer a causa de la sobreexplotación, situación teórica popularizada por Hardin (1968), con el nombre de «la tragedia de los comunes», quien en su artículo concluye: «Ahí está la tragedia. Cada hombre se encuentra atrapado en un sistema que lo compele a aumentar su ganado sin ningún límite, en un mundo que es limitado. La ruina es el destino hacia el cual todos los hombres se precipitan, persiguiendo cada uno su propio interés en una sociedad que cree en la libertad de los bienes comunes». (Hardin, 1968, p. 1244).

Sin embargo, a raíz de las contribuciones de Ostrom fue mayoritariamente aceptado en la disciplina que las personas sí son capaces de «mirar más allá de sus narices», de llegar a acuerdos y honrarlos, con el fin enfrentar amenazas mayores como el agotamiento de un recurso. Aunque estas constataciones no se contraponen con la agenda de la Ess, pues confirmarían que es posible la denominada tercera vía para gestionar los recursos, más allá del Estado y de la propiedad privada. No se hace relación aquí al capitalismo y a la economía de mercado como los causantes del egoísmo o promotores de la solidaridad.

En su lugar, para Ostrom lo importante es comprender por qué algunos sistemas autoorganizados sobreviven durante largas épocas mientras que otros colapsan apenas iniciados. Su conclusión es que no existe una regla específica, sino una serie de principios subyacentes, como la comunicación que debe haber entre las partes, la transparencia en la fijación y aplicación de sanciones, o la democracia que debe existir para que los acuerdos sean efectivos - algo con lo que los autores de la ess probablemente estarían de acuerdo-. Estudios empíricos posteriores han encontrado que la imposición de reglas imperfectamente monitoreadas - como sucede en la realidad-, tenía un impacto negativo en el nivel de cooperación cuando se comparaba con la cooperación lograda mediante la discusión y el acuerdo endógeno (Cárdenas, Stranlund y Willis, 2000), (Cárdenas, 2000).

Desde las distintas acepciones del término, la cooperación solo es posible mediante la solidaridad..$^{9}$ Es decir, distintos tipos de solidaridad deben existir entre personas que administran exitosamente bienes de propiedad común. Sin embargo, hay que señalar que la cooperación entre humanos no se limita a estos grupos. En realidad, la capacidad de cooperar a gran escala es una característica destacada de nuestra especie; $y$ ha constituido un enigma para toda 
una generación de científicos en diferentes disciplinas. La cooperación entre humanos ha sido considerada enigmática porque no puede explicarse mediante un simple mecanismo de selección genética; porque a diferencia de algunas especies de insectos como las hormigas, las abejas o las termitas, ésta se da entre individuos no emparentados. Por otro lado, otros modelos desarrollados, como el modelo de cooperación recíproca (Axelrod, 1985), solo podrían sustentar la cooperación entre grupos pequeños de personas entre quienes la probabilidad de volver a interactuar sea relativamente alta. Esto ha llevado a un grupo importante de economistas a considerar que la especie humana ha evolucionado para llegar a ser una «especie cooperativa» (Bowles y Gintis, 2011), con lo cual la idea de que las personas son solidarias ha pasado a ser dominante en la disciplina. ${ }^{10}$

Bowles y Gintis (2011) son dos autores representativos de un grupo significativo de economistas contemporáneos que suscriben la idea de que las personas son, por naturaleza, cooperativas. En una adaptación de la metodología neoclásica a este tipo de postulados, estos autores han incorporado las «preferencias sociales» a la función de utilidad de las personas, con lo cual puede establecerse que preferirían actuar con solidaridad, o por alguna motivación social, antes que con egoísmo, al menos hasta el punto en que esa acción no sea lo suficientemente costosa como para que la utilidad marginal que se pierde - por pagar el costo de ser solidario- supere a la utilidad marginal que le produce la misma acción. Esto implica que podría derivarse una suerte de «demanda de solidaridad». ${ }^{11}$

Aun estando en desacuerdo con esta aproximación metodológica - hay que considerar que la idea de las preferencias sociales tiene feroces críticas incluso desde dentro del mainstream; a manera de ilustración puede consultarse a Binmore (2010) - , hay que reconocer que proporciona ciertas ventajas a la hora de evaluar empíricamente el comportamiento de las personas, al definir con precisión algunas de sus variaciones. Por ejemplo, la reciprocidad implica que tenemos ciertas preferencias por actuar bien con quienes han actuado bien con nosotros, $y$ por actual mal con quienes han actuado mal con nosotros (Rabin, 1993). El altruismo implica que tenemos cierta preferencia por favorecer a otro, aún a costa del beneficio propio, incluso si no hay posibilidad de interactuar repetidamente - es decir, descartando que sea reciprocidad-. El bienestar social (Andreoni y Miller, 2002) implica que tenemos cierta preferencia por mejorar el pago de la sociedad en su conjunto. En este caso, si tengo que sacrificar parte de mi pago para conseguir que la sociedad en conjunto obtenga un pago mayor, es probable que lo haga. El cumplimiento de las normas implica que tenemos cierta preferencia por actuar según las buenas costumbres, y éstas están definidas por las normas sociales. En este caso, si tengo que cumplir una norma, aun sacrificando cierto pago, es probable que lo haga. Por ejemplo, si tengo que mentir para obtener cierto pago es probable que prefiera renunciar al mismo antes que violar una regla de comportamiento (López-Pérez y Spiegelman, 2012). Finalmente, la equidad implica que tenemos cierta preferencia por minimizar las desigualdades entre nuestros pagos y los pagos de las otras personas. En este caso, estaríamos dispuestos a reducir los pagos de otra persona con tal de equipararlos con los nuestros (Fehr y Schmidt, 1999), (Bolton y Ockenfels, 2000).

Con este tipo de criterios, un grupo importante de economistas, bajo el paraguas de la economía del comportamiento, se han dedicado a observar el tipo de respuesta que tienen las 
personas en situaciones controladas, definidas por la teoría de juegos, planteadas en un laboratorio, con el fin de caracterizar el comportamiento humano. Los diferentes estudios realizados con diferentes grupos de participantes alrededor del mundo han llegado a descartar que las decisiones de las personas estén motivadas únicamente por el egoísmo o la búsqueda de la maximización de las ganancias. Se ha demostrado que los criterios de justicia y de comportamiento decente respecto a los pares sociales son importantes, no solo para los humanos, sino también incluso para especies animales como los primates (Brosman, 2008); aunque en el caso de los humanos, la capacidad de cooperación sobresale de entre todas las demás.

A la luz de este tipo de argumentos, parece un hecho incuestionable que las personas cooperan, alrededor del mundo, y a lo largo de la historia, y sin mirar el sistema económico en el que participan. Pese a que los mecanismos y las razones por las cuales se da esta cooperación -o por los que se inhibe - son material de un largo debate que escapa al alcance del presente artículo, un importante - quizás mayoritario- grupo de economistas coincidirían en señalar que la cooperación es posible gracias a la existencia de normas sociales, las cuales honramos porque no hacerlo nos provoca emociones negativas, lo mismo que si otros no lo hacen. ${ }^{12} \mathrm{De}$ esta manera, equiparando normas morales y solidaridad - algo con lo cual Émile Durkheim no hubiera estado en desacuerdo- puede establecerse la primera afirmación que busca este artículo que es que, en el capitalismo y la economía de mercado, la solidaridad sí es posible, y de hecho se observa contundentemente.

Otros argumentos a favor de la presencia de la solidaridad — en la forma de valores morales- en el capitalismo y la economía de mercado pueden encontrarse incluso en autores críticos a este sistema dominante, desde disciplinas como la sociología. Por ejemplo, Boltanski y Chiapello (2002) sostienen que las personas necesitan «poderosas razones morales» para adherirse al capitalismo. «El capitalismo no puede prescindir de una orientación hacia el bien común de la que extraer razones por las cuales merece la pena adherirse a él», (Boltanski y Chiapello, 2002). Los autores realizan estas afirmaciones en el contexto de procurar una descripción del «espíritu del capitalismo» moderno, haciendo referencia al sentido weberiano del término. ${ }^{13}$ De esta forma, los autores son conscientes de que el capitalismo no podría lograr el compromiso de las personas que en él participan — sean capitalistas o trabajadores-, a no ser que cuente con un sistema de normas morales que los motive.

No es intención en este artículo abundar en las características de este «nuevo espíritu del capitalismo» descrito por Boltanski y Chiapello, aunque quizás sí amerite destacar lo que los autores entienden por la relación existente entre el capitalismo y sus críticas. Para estos autores, las críticas al capitalismo, provenientes de «aquellos a quienes indigna y se oponen a él» juegan un rol clave «para encontrar los puntos de apoyo morales que le faltan e incorporar dispositivos de justicia». En otros términos, la crítica le permitiría al capitalismo evolucionar, incorporando «en su seno una parte de los valores en nombre de los cuales era criticado». Ésta sería la explicación que proporcionan para entender por qué el sistema capitalista se ha mostrado infinitamente más robusto de lo que habían pensado sus detractores - Marx en primer lugar-.

De tal forma, si el capitalismo tiene la capacidad de incorporar aquellos valores cuya carencia ha sido objeto de la crítica, ¿qué puede hacer suponer que en los tiempos modernos no haya superado ya las nociones de egoísmo y glotonería de las que ha sido acusado desde sus 
orígenes? Para ilustrar las implicaciones de este razonamiento desde las ideas de Boltanski y Chiapello, considere, por ejemplo, que en el ámbito de la administración de empresas desde hace algunos años atrás, la jerarquía es una forma de coordinación a eliminar debido a que reposa sobre una relación de dominación. ${ }^{14}$ No se trata solo de liberar a los directivos, sino a todos los trabajadores de la empresa. Con la llegada de la era del conocimiento se acepta de forma general en nuestros días que la jerarquía se ha convertido en un modo de organización obsoleto.

Retornando al objeto del presente ensayo, cabría preguntarse ¿por qué las empresas capitalistas no habrían de incorporar en sus prácticas valores que permitan la participación comprometida, tanto de sus cuadros como de sus demás trabajadores, como mecanismos de motivación que vayan más allá de la coerción y de los incentivos monetarios? Tomar en cuenta que los sicólogos del trabajo han puesto de manifiesto lo insuficiente que resulta la remuneración para activar el compromiso y el entusiasmo por la tarea asignada. En el mejor de los casos, el salario se constituiría en una razón para quedarse en un puesto y no para comprometerse con él ¿Qué argumentos pueden presentarse para sostener que las «unidades solidarias» están investidas de valores superiores de solidaridad que les permiten tener mejores resultados de eficiencia mediante el aumento de la cooperación y la disminución de los conflictos?

Si las fronteras en cuanto a las prácticas de las «unidades solidarias» y las empresas capitalistas son tenues - como se ha ejemplificado arriba-, y se pone en tela de duda la existencia de una diferencia clara respecto a los valores de solidaridad, la pretensión de la Ess de constituirse en una alternativa al capitalismo quizás está sobredimensionada. Esto no quiere decir que sus esfuerzos por integrar a los sectores sociales marginados a los procesos productivos, distributivos, de financiamiento y de consumo, sean en vano o no merezcan la pena; pero quizás sea la hora de aceptar que en el capitalismo y la economía de mercado sí surge la solidaridad, y de orientar mayores esfuerzos a la comprensión de las condiciones bajo las cuales ésta surge de mejor manera, para lo cual quizás sea conveniente incorporar ideas, metodologías, conceptos y experiencias que surgen desde otras disciplinas.

Para terminar esta sección, antes de pasar a las conclusiones, se exponenr dos referencias según las cuales no solo que el capitalismo no erosiona los valores morales, sino que los promueve.

En primer lugar, Deirdre McCloskey (2006) en su libro Las virtudes burguesas: Ética para la era del comercio, argumenta que ciertas virtudes como el amor, la fe, la esperanza, la humildad, el valor, la prudencia y la justicia son promovidas por la práctica del comercio y el capitalismo. ${ }^{15}$ Interesantemente, en su calidad de historiadora, la autora asegura que es abrumadora la evidencia a favor de que el capitalismo no erosiona la solidaridad, sino que la promueve:

La tasa de homicidios en pueblos en el siglo XIII, por tomar el caso inglés, era mayor que en lugares comparables contemporáneos. Campesinos medievales ingleses eran geográficamente móviles, «fragmentando» sus vidas. La imaginada familia extendida de la vida «tradicional» nunca existió en Inglaterra. $\mathrm{O}$, cambiando de lugar: la vida «tradicional» de la familia americana a la antigua ha sido grandemente exagerada. Los mir rusos no eran ni viejos ni igualitarios, sino un producto de la imaginación romántica alemana. Los campesinos vietnamitas no vivían en comunidades tranquilas y cerradas. (McCloskey, 2006, p. 141). 
La autora, en cierto sentido, se pregunta ¿cómo es que «todos» creen en la pérdida de la solidaridad, como resultado del debilitamiento de las formas tradicionales de vida, excepto los historiadores que han visto la evidencia de forma comparativa?

En segundo lugar, Paul J. Zak (2008) provee abundante evidencia que converge a la idea de que el intercambio de mercado moderno es inconcebible sin la presencia de valores morales, que son más sólidos que en otros tipos de sistemas debido a que la economía de mercado requiere de una gran flexibilidad institucional, es decir, la capacidad de poder modificar las reglas del juego; lo que le permitiría adaptarse a las nuevas demandas - de manera emblemática, la inflexibilidad institucional puede reflejarse en los código morales de la mayoría de sociedades islámicas-.

Entre otras cosas, Zak también destaca que la «competencia egoísta en los mercados» es una noción incompleta y mal entendida de La riqueza de las naciones, de Adam Smith. Completando esta idea con las expresadas en su otra obra Teoría de los sentimientos morales (Smith, 2004), se entiende que el self-interest o self-love - traducido muchas veces de forma errónea como egoísmo sumado a la capacidad de empatía - sería indispensable para que las personas aprendan a seguir las reglas sociales, pues permite tomar en cuenta los sentimientos, de gratitud o de resentimiento, de los demás. Detrás de cualquier norma social o de justicia estaría el deseo de ser elogiados o merecer esos elogios - por parte del observador imparcial一, y el deseo de evitar la culpa o de merecerla -igualmente-. Estos sentimientos servirían de indicadores de la armonía que tenemos con el orden y las normas locales. ${ }^{16}$

De esta forma se han expuesto una serie de argumentos contemporáneos a favor de la idea de que el capitalismo y la economía de mercado no destruyen los valores morales y, por el contrario, requiere de ellos para poder funcionar. A continuación se formulan las principales conclusiones de este ensayo.

\section{CONCLUSIONES}

Equiparando la solidaridad a ciertos valores morales y normas que nos hacen actuar en función de otros y de la colectividad, en contraposición del egoísmo y el individualismo; y a la luz de los argumentos expuestos; puede concluirse que en el capitalismo y la economía de mercado sí pueden surgir la solidaridad, y de hecho ocurre. Aunque se han mencionado autores críticos a la globalización — como es el caso de Martínez González-Tablas - o al capitalismo - como es el caso de Boltanski y Chiapello- se ha buscado no debatir sobre este tipo de posturas a no ser dentro de la interrogante de si estos procesos destruyen o no la capacidad de cooperación de las personas.

Tampoco se ha pretendido invalidar a la ess como disciplina, más allá de la pretensión de constituirse en una alternativa al capitalismo. Es más, considero que los esfuerzos por incluir en la economía a los sectores vulnerables de la población — no solo hablando a nivel local, pero nacional e incluso mundial- no solo que son válidos, sino que son loables y dignos de admiración y respeto. Pero, abro la posibilidad de que esos esfuerzos no estén atentando en contra del capitalismo, sino constituyéndose en una forma de volverlo más incluyente y justo.

En este sentido, rescato como válido el papel que juega la crítica en el capitalismo según el criterio de Boltanski y Chiapello; por lo que un fortalecimiento de los argumentos de la Ess, a 
favor de la justicia y la equidad, podría ser de gran utilidad en el afán de construir un mundo más justo y seguro para todos. Con este afán podría ser de utilidad para los autores interesados en esta temática profundizar en la compresión de la cooperación y de las condiciones bajo las cuales surge y es sostenible, para cual puede ser de utilidad echar una mirada a las ideas, las metodologías y experiencias que se generan en otras disciplinas.

A este respecto, considero que un estudio de la solidaridad no debiera desconocer los aportes conceptuales de autores clásicos como Durkheim para quien la fraternidad humana o fraternidad universal solo puede surgir de una sociedad vasta, caracterizada por una alta división del trabajo, aunque su consecución no es automática, pues requiere de la interacción de los agentes para poder adaptarse a las nuevas circunstancias. Desde mi entender, esta interacción es la misma que busca facilitar la Ess, y es el mismo fenómeno que estudia autores desde la economía como Ostrom.

\section{NOTAS}

1 En esta visión, el capitalismo surge de la producción simple de mercancías, negándola al separar la posesión y la utilización de los medios de producción y distribución. Los medios de producción y distribución se vuelven capital a medida que se concentran en manos de una minoría, mientras que la mayoría se limita a la posesión de su capacidad individual de trabajo

2 Según Singer, los principios organizadores de las cooperativas serían: i) posesión colectiva de los medios de producción por las personas que los utilizan para producir, ii) gestión democrática de la empresa por participación directa o por representación, iii) división del ingreso neto entre cooperantes por criterios aprobados después de discusión y negociaciones entre todos, iv) asignación del excedente anual también por criterios aprobados entre todos, v) cuota básica de capital de cada cooperante no remunerada, y vi) sumas adicionales prestadas a la cooperativa a tasas de interés más baja del mercado. 3 Término usado por el autor, que en cierta forma revela que él considera que el mercado promueve ciertos beneficios respecto a la eficiencia en la asignación de recursos, al mejoramiento de los beneficios, $\mathrm{y}$ al «recto comportamiento».

4 La metáfora hace alusión principalmente al funcionamiento social y económico del sistema. La tendencia a la concentración de capital, la productividad decreciente, las crisis periódicas de sobreproducción, etc., generaría una clase proletaria cada vez más numerosa y combativa que conduciría inevitablemente a la revolución socialista.

5 Históricamente, esta obra está enmarcada en el triunfo del fascismo - de la barbarie nazi-, la perversión autoritaria estalinista del socialismo y la asombrosa capacidad integradora y manipuladora de la cultura capitalista de masas. A su pesar, esa capacidad podía neutralizar la rebelión de la clase trabajadora y de todo pensamiento genuino.

6 El sentido de la justicia caracteriza la obra de Horkheimer alejándolo a la vez de la metafísica y del positivismo. Esa misma perspectiva llevó a su pensamiento a configurarse como teoría crítica de la sociedad, con la intención práctica de construir una sociedad «racional, justa y humana».

7 Notar la relación que sugiere el autor entre el positivismo y la cultura comercial, y la forma en que está intrínsecamente reñida con normas superiores.

8 Hay que señalar que el autor sí reconoce que son cada vez más frecuentes los trabajos que abordan problemas como los costos de transacción (Coase, 1937) o la información asimétrica (Akerlof, 1970).

9 Sea que se entienda por solidaridad el sentimiento de unidad basado en las metas comunes; o de forma general, el conjunto de lazos sociales que unen entre sí a los miembros de una sociedad.

10 Samuel Bowles y Herbert Gintis publicaron en 2011 su libro A cooperative species: human reciprocity and its evolution, donde desarrollan la idea de que los seres humanos no son egoístas como suponía la 
teoría convencional. Ellos son autores influyentes en el pensamiento económico dominante.

11 Se refiere específicamente a la relación inversa existente entre el precio de un bien y su cantidad demandada.

12 Muchos economistas han empezado a mostrar interés en el papel de las emociones en el comportamiento, dando lugar al surgimiento de nuevas ideas y formas de estudiarlas, agrupadas en la Neuroeconomía. Sin embargo, incluso aquellos economistas más ortodoxos, interesados únicamente en las preferencias reveladas, podrían estar de acuerdo que las emociones condicionan nuestras respuestas, aunque sea como parte de la función de utilidad.

13 Para Max Weber, el espíritu del capitalismo hace referencia al conjunto de elementos éticos que, si bien ajenos en su finalidad a la lógica capitalista, inspiran a los empresarios en sus acciones a favor de la acumulación de capital.

14 «Los motivos para invocar este cambio antijerárquico son a menudo de orden moral y participan de un rechazo más general de las relaciones dominante-dominado» (p. 112).

15 Según la definición ofrecida por la autora, una virtud es un hábito adquirido cuya posesión facilita el logro de ciertos bienes, lo que acerca el concepto de virtud al de norma social, lazos sociales o sistemas de valores con los que se hace referencia a la solidaridad en el presente artículo.

16 A propósito de esto, Vernon Smith (2016) formula una dura crítica a la noción de las preferencias sociales manejada por muchos economistas y que se ha explicado arriba, pero que ahora no amerita profundización.

\section{REFERENCIAS}

Acosta, A., Martínez, E. y Coraggio, J. L. (2011). Economía social y solidaria: el trabajo antes que el capital. Quito, Ecuador: Abya Yala.

Akerlof, G. A. (1970). The Market for «Lemons»: Quality Uncertainty and the Market Mechanism. The Quaterly Journal of Economics, 84(3), 488-500.

Andreoni, J. and Miller, J. (2002). Giving acoording to GARP: An experimental test of the consistensy of preferences for altruism. Econometrica, $70(2), 737-753$.

Axelrod, R. (1985). The evolution of cooperation. New York, UsA: Basic Books.

Binmore, K. (2007). Playing for real: A text on Game Theory. Oxford, uk: Oxford University Press.

Binmore, K. (2010). Social norms or social preferences? Mind \& Society, 9(2), 139-157.

Binmore, K. and Shaked, A. (2010). Experimental economics: Where next? Journal of Economic Behavior \& Organization, 73(1), 87-100.

Boltanski, L. y Chiapello, E. (2002). El nuevo espíritu del capitalismo. Madrid, España: Akal.

Bolton, G. E. and Ockenfels, A. (200o). A Theory of equity, reciprocity, and competition. American Economic Review, 9o(1), 166-193.

Bowles, S. and Gintis, H. (2011). A cooperative species: Human reciprocity and its evolution. Princeton, USA: Princeton University Press.

Boyd, R. and Richerson, P. (2005). The origin and evolution of cultures. Oxford, uK: Oxford University Press.

Brosman, S. (2008). Fainess and other-regarding preferences in nonhuman primates. En P. J. Zac, Moral Markets: The critical role of values in the economy. Princeton, USA: Princeton University Press.

Cárdenas, J. C., Stranlund, J. and Willis, C. (200o). Local environmental control and institutional crowding-out. World Development, 28(10), 1719-1733.

Cárdenas, J. C. (2000). How Do Groups Solve Local Commons Dilemmas? Lessons from Experimental Economics in the Field. Environment, Development and Sustainability, 2, 305-322. 
Charness, G. and Rabin, M. (2002). Understanding social preferences with simple tests. Quaterly Journal of Economics, $117(3), 817-869$.

Chen, Y. and Xin Li, S. (2009). Group identity and social preferences. American Economic Review, 99(1), 431-457.

Coase, R. H. (1937). The Nature of the firm. Economica, 4(16), 386-405.

Coraggio, J. L. (2008). Economía social, acción pública y política: hay vida después del neoliberalismo. Buenos Aires, Argentina: Fundación Centro Integral Comunicación, Cultura y Sociedad (ciccus).

Dales, J. H. (1968). Polution, property and prices: an essay in Policy-making and Economics. Torornto, Canada: University of Toronto Press.

Durkheim, É. (1967). De la división del trabajo social. Buenos Aires, Argentina: Schapira Editor.

Elster, J. (2014). Razón y racionalidad. Buenos Aires, Argentina: Amorrortu.

Fehr, E. and Gächter, S. (2002). Altruistic punishment in humans. Nature, 415, 137-140.

Fehr, E. and Schmidt, K. M. (1999). A Theory of fairness, competition, and cooperation. Quaterly Journal of Economics, 114(3), 817-868.

Gaiger, L. I. (2007). La economía solidaria y el capitalismo en la perspectiva de las transiciones históricas. En J. L. Coraggio, La economía solidaria y el capitalismo en la perspectiva de las transiciones históricas. Buenos Aires, Argentina: Altamira.

Gordon, H. S. (1954). The economic theory of a common-property resourse: The Fishery. Journal of Political Economy, 62, 124-142.

Guerra, P. (2014). Socioeconomía de la solidaridad: una teoría para dar cuenta de las experiencias sociales y económicas alternativas. Bogotá, Colombia: Ediciones Universidad Cooperativa de Colombia.

Güth, W., Schmittberger, R. and Schwarze, B. (1982). An experimental analysis of ultimatum bargaining. Jornal of Economic Behavior \& Organization, 3(4), 367-388.

Hardin, G. (1968). The Tragedy of the Commons. Science, 162(3859), 1243-1248.

Hayek, F. A. (2011). The constitution of liberty. London, UK: The University of Chicago Press, Ltd.

Henrich, J. (2005). Cultural evolution of human cooperation. En The origin and evolution of cultures. Oxford, uk: Oxford University Press.

Henrich, J., Boyd, R., Bowles , S., Camerer, C., Fehr, E., Gintis, H. and McElreath, R. (2001). In search of homo economicus: Behavioral experiments in 15 small-scale societies. American Economic Review, 91(2), 73-78.

Herrmann, B., Thöni, C. and Gächter, S. (2008). Antisocial punishment across societies. Science, 319, 1362-1367.

Hirsch, F. (1976). Social limits to growth. Cambridge, MA and London: Harvard U. Press.

Hirschman, A. O. (1982). Rival interpretarion of market society: civilizing, destructive or feeble? Journal of Economic Literature, 2o(4), 1463-1484.

Horkheimer, M. (2002). Crítica de la razón instrumental. Madrid, españa: Trotta.

Laville, J. L. (2009). Crisis capitalista y economía solidaria: una economía que emerge como alternativa real. Barcelona, España: Icaria.

Leibniz, G. W. (1991). Los elementos del derecho natural. Madrid, España: Tecnos.

López-Pérez, R. and Spiegelman, E. (2012). Why do people tell the truth? Experimental evidence for pure lie aversion. Experimental Economics, 1-15. 
Malthus, T. R. (2007(1798)). Ensayo sobre el principio de la población. Buenos Aires, Argentina: Claridad. Mandeville, B. (2003). La fábula de las abejas o los vicios privados hacen la prosperidad pública: comentario crítico, histórico y explicativo de F. B. Kaye. México DF, México: Fondo de Cultura Económica. Martínez González-Tablas, Á. (200o). Economía política de la globalización. Barcelona, España: Ariel. Marx, C. y Engels, F. (2006). Manifiesto: tres textos clásicos para cambiar el mundo. (s. c.): Ocean Sur. McCloskey, D. N. (2006). The Bourgeois virtues: Ethics for an age of commerce. Chicago, usa: The University of Chicago Press.

Montesquieu, C. (1987). Del espíritu de las leyes. Madrid, España: Tecnos.

Naredo, J. M. (2015). La economía en evolución. Madrid: Siglo xxi de España Editores s. A.

Ostrom, E. (2011). El gobierno de los bienes comunes: La evolución de las instituciones de acción colectiva. México, DF, México.: Fondo de Cultura Económica.

Paine, T. (1951). The rigths of man. New York, UsA: E. P. Dutton.

Polanyi, K. (1992). La gran transformación: los orígenes políticos y económicos de nuestro tiempo. México DF, México: Fondo de Cultura Económica.

Rabin, M. (1993). Incorporating fairness into game theory and economics. The American Economic Review, $83(5), 1281-1302$.

Razeto, L. (1984). Economía de solidaridad y mercado democrático. Santiago de Chile, Chile: Academía de Humanismo Cristiano.

Razeto, L. (1997). Los caminos de la economía de solidaridad. Buenos Aires-Madrid. Lumen-Hvmanitas. Ricard, S. (1781). Traité général du commerce. Amsterdam, Holland: Chez E. van Harrevelt et Soeters.

Simmel, G. (1955). Conflict and the web of group affiliations. Glecoe, Il: The Free Press.

Simmel, G. (2013). Filosofía del dinero. Madrid, España: Capitán Swing.

Singer, P. (200o). Possibilidade da Economia Solidaria no Brasil. cut. Sindicalismo e economia solidaria. Sao Paulo, Brasil: Reflexoes sobre o projeto da cut.

Singer, P. (2007). Economía solidaria: un modo de producción y distribución. En J. L. Coraggio, La economía social desde la periferia: contribuciones latinoaméricas. Buenos Aires, Argentina: Altamira.

Singer, P. (2012). A experiência brasileira nas políticas públicas para a Ess. En J. L. Coraggio, Conocimiento $y$ políticas públicas de economía social y solidaria: problemas y propuestas. Quito, Ecuador: IAEN. Smith, A. (2004). La teoría de los sentimientos morales. Madrid, España: Alianza.

Smith, V. L. (2016). The Fair and Impartial Spectator. Econ Journal Watch, 13(2), 330-339.

Voutto, M. (2003). Economía social: precisiones conceptuales y algunas experiencias hitóricas. Buenos Aires, Argentina: Fundación OSDE: Altamira.

Williams, B. (1996). Descartes: el proyecto de la investigación pura. Madrid, España: Cátedra.

Zak, P. J. (2008). Moral markets. The role of values in the economy. Princeton, UsA: Princeton University Press. 